
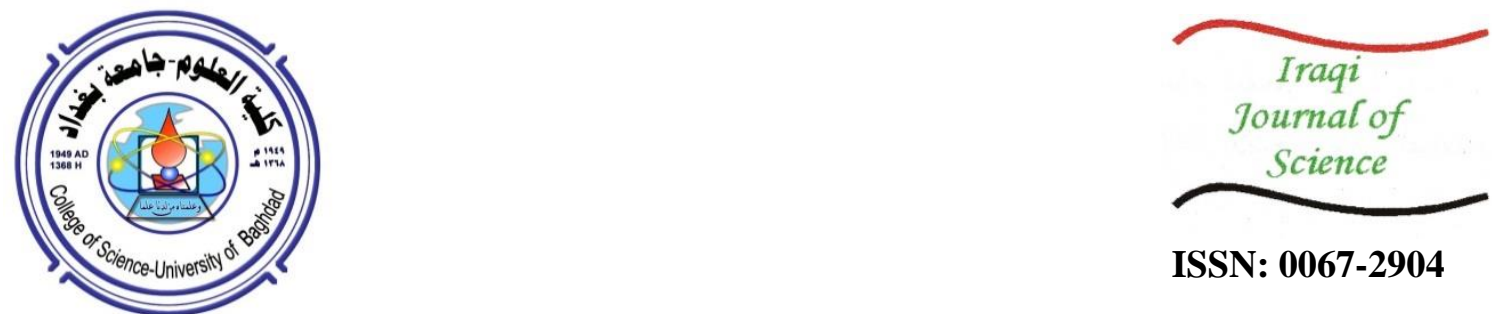

ISSN: 0067-2904

\title{
Density - Velocity Relationship and Prediction of Lithology Variation Using Physical Analysis in Kf-4 Well of The Kifl Oil Field, Yamama Formation, South of Iraq
}

\author{
Abdulaziz R. Alobaidy*, Ahmed S. Al-Banna \\ Department of Geology, College of Science, University of Baghdad, Baghdad, Iraq
}

Received: 3/12/2020

Accepted: 16/1/2021

\begin{abstract}
The density-velocity relation is an important tool used to predict one of these two parameters from the other. A new empirical density -velocity equation was derived in Kf-4 well at Kifl Oil Field, south of Iraq. The density was derived from Gardner equation and the results obtained were compared with the density log (ROHB) in Kl-4 well. The petrophysical analysis was used to predict the variations in lithology of Yamama Formation depending on the well logs data, such as density, gamma, and neutron logs. The physical analysis of rocks depended on the density, $\mathrm{Vp}$, and Vs values to estimate the elastic parameters, i.e. acoustic impedance (AI) and $\mathrm{Vp} / \mathrm{Vs}$ ratio, to predict the lithology and hydrocarbon indicators. According to the results of physical properties, Yamama Formation is divided into five units in Kf-4 well at Kifl Oil Field. The lithology of Yamama Formation was found to consist of limestone, dolomite, shale, and anhydrite rocks.
\end{abstract}

Keywords: Vp/Vs ratio, Yamama Formation, Rock physics analysis, Kifl Oil Field, Acoustic Impedance (AI), Iraq
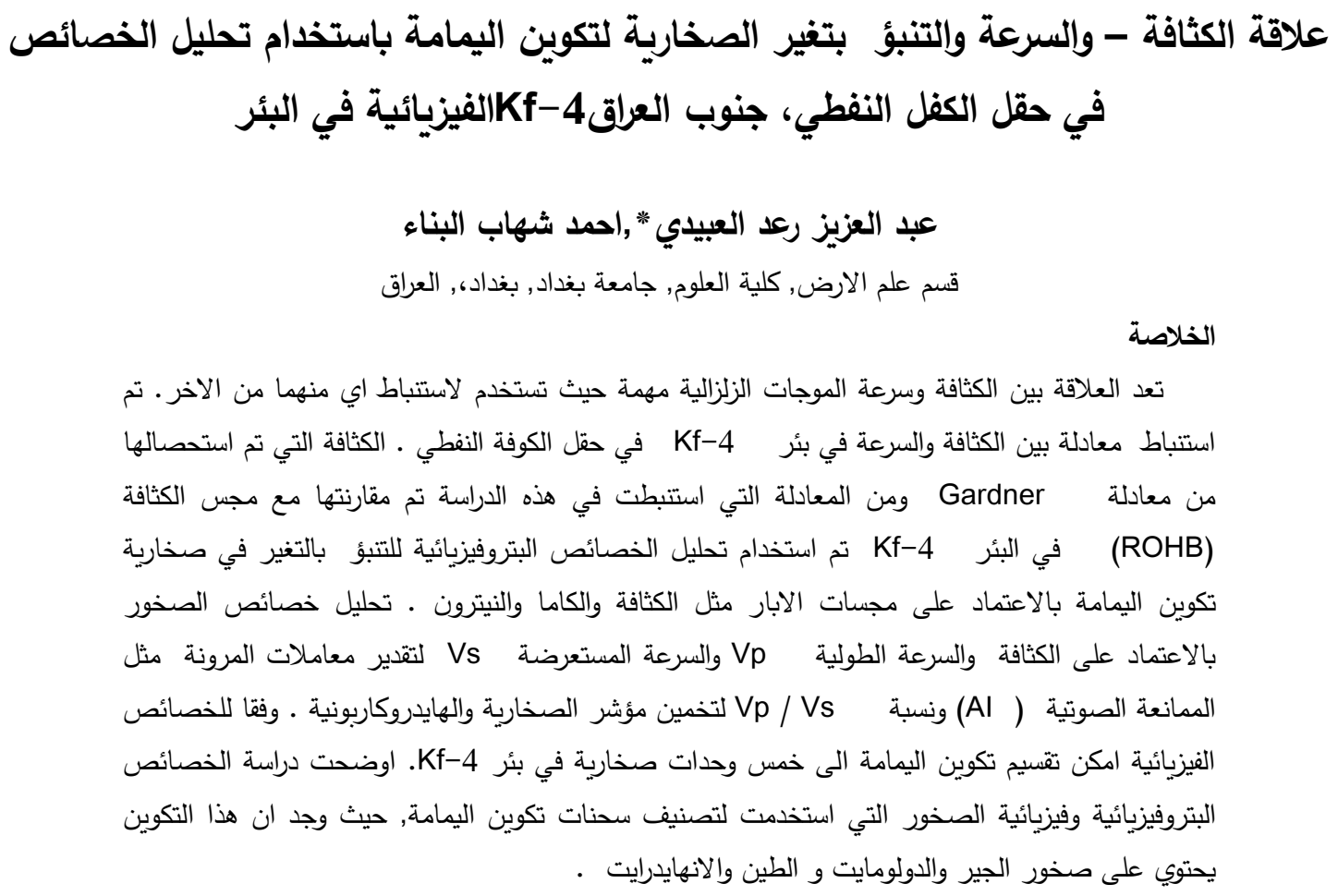

*Email: aziz.alubaidyy@gmail.com 


\section{Introduction}

Density and velocity are considered as fundamental properties of rocks material. These properties are determined by laboratory and field measurements to explain the geometry of the geological units of the earth. Density and velocity measurements are obtained by applying many methods, including vertical seismic profile (using a source on surface and receiver in downhole), wireline borehole logs of different rocks, and field and laboratory measurements on hand samples [1]. Both density and velocity are affected by composition, cementation, granular nature of the rock, environmental pressure, geologic age, depth of burial, porosity, and fluid content [2]. Density can be obtained from seismic data by seismic inversion and geostatistical methods, where non-linear, linear, and multi-linear relationships between the rock properties and well logs seismic data are calculated at the well location [3]. Many empirical relationships between density and velocity were obtained in global and local areas to predict one from the other. The petro-physical analysis is considered as an important part of reservoir characterization process, linking the results to the core data. This analysis is used to transform the wireline log data, such as gamma, sonic, neutron, cement bond log, caliper log, and resistivity log, etc., into reservoir characterizations, such as lithological prediction, permeability, porosity, and hydrocarbon and water saturation [4]. The rock physics has been evolved to become a principal tool of the determination of reservoir geophysics properties and an important part of quantitative seismic interpretation. Rock physical diagnostic properties of depositional texture were used to confirm the results of the petrophysical analysis and to minimize errors in prediction and interpretation [5]. Rock physics depends on measurements of density and compressional $(\mathrm{Vp})$ and shear $(\mathrm{Vs})$ velocities to define the elastic properties, such as shear impedance (SI), bulk modulus (B), shear modulus $(\mu)$, Lame's parameter $(\lambda)$, which includes Lambda-Rho and Mu-Rho, Poisson's ratio, velocity ratio ( $\mathrm{Vp} / \mathrm{Vs})$, and acoustic impedance (AI). The cross plot of $\mathrm{Vp} / \mathrm{Vs}$ ratio and $\mathrm{AI}$ can be used to predict the lithological facies and pore fluid indicators and discriminate between hydrocarbon and nonhydrocarbon zones [6]. This study attempts to find the relation between the density and velocity and to investigate the physical properties of Kifl Oil Field depending on the well log data of Kf-4 well.

\section{Location and Geological Setting of the study Area}

The Kifl Oil Field is located in the Kifl area between Najaf and Karbala cities, about 30 $\mathrm{Km}$ to the southwest of the Hilla city in the middle of Iraq. The study area is tectonically lying in the stable Mesopotamian basin between the Zagros fold belt and Arabian shield in the Euphrates Subzone [7], while it was described as being located in the tectonic transition zone in another study [8]. The well Kf-1 was drilled in the years 1954-1960, while the well Kf-4 was drilled in 1984. A 3D seismic survey was performed by the Iraqi Oil Exploration Company (OEC) for the period 1991-1992. The coordinates of the Kf- 4 well are represented by latitudes $32^{\circ} 15^{\prime} 16^{\prime \prime} \mathrm{N}$ and longitudes $44^{\circ} 07^{\prime} 46^{\prime \prime}$ E. [9] , as shown in Figure 1. 


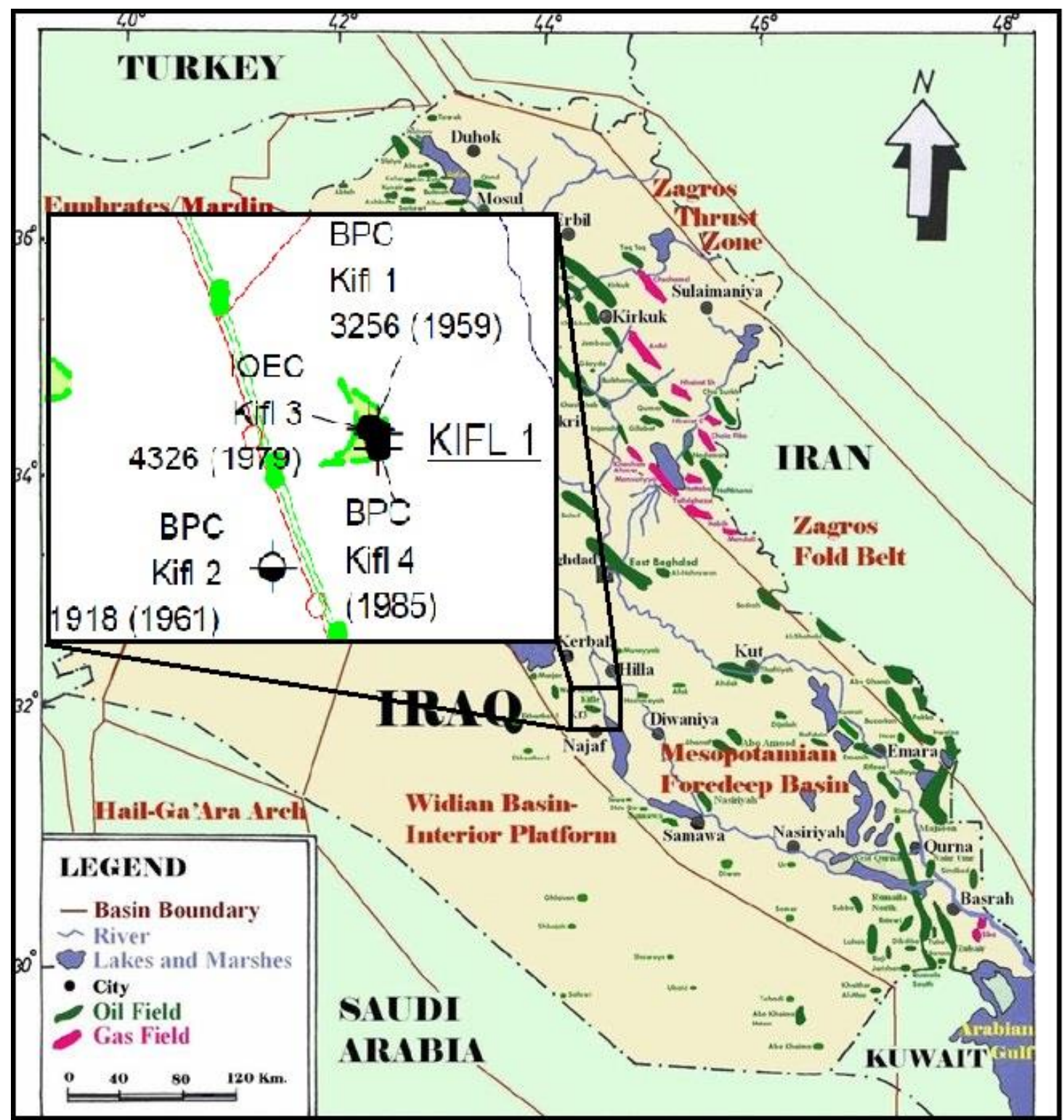

Figure 1- A map of the locations of gas and oil fields in Iraq showing the well Kf-4. Modified after [10].

\section{Methodology}

The data used in this study are Wire-line logs of the well Kf-4, including sonic (DT), gammaray (GR), density (RHOB), and neutron porosity (NPHI) logs, which were discussed and interpreted by using Petrel software (V.2017). The well logs data was processed to remove the bad and scattered data, such as the spikes and high frequency noise. The procedure of the analysis of the well log data was divided into three major stages; the first stage is represented by studying the density- velocity relationship using the RHOB and DT logs data. The density was estimated using Gardner equation in Petrel software 2017. The field survey and processing were performed by the OEC in 1984 [9].

Density $=0.229907 * \mathrm{DT}^{\wedge} 0.25 \ldots \ldots \ldots$ Gardner equation (Petrel software (V.2017))

where $\mathrm{Dt}=$ Sonic $\log$ value

At the same time, the density was estimated from an empirical equation of density/velocity obtained depending on the log data in Kf-4 well, as illustrated in Figure 2. The second stage is the petro-physical analysis, which involved a cross plot interpretation of sets of data logs, which included gamma, density, and neutron logs. In this interpretation, the values of 
gamma, density, and porosity are good indicators of shale, sandstone, and hydrocarbon zone, respectively [5]. The third stage is the rock physical analysis that depended on the elastic parameters which were estimated from the values of density, Vp, and Vs. Vp was determined from the equation Velocity $(\mathrm{Vp})=1 /$ Sonic, whereas Vs was determined from Vp by using the equation of Greenberg-Castagna used in Petrel software 2017. The equation of shale determination is $\mathrm{Vs}=-867.4+0.77 \mathrm{Vp}$ and the equation of sandstone is $\mathrm{Vp}=-855.9+0.8042$ $\mathrm{Vp}$. In this study, we used $\mathrm{Vp} / \mathrm{Vs}$ ratio and AI cross-plot to predict the lithology, where the high value of $\mathrm{Vp} / \mathrm{Vs}$ indicated shale while the low value of $\mathrm{Vp} / \mathrm{Vs}$ indicated sandstone, as shown in Figure 6.

\section{Well data Discussion and interpretation}

\section{- Density - velocity relationship}

The empirical relationship between the density and velocity was used to predict density from velocity and verse versa. These relationships are different from a region to another, depending upon depositional history, physical properties of rocks, and geological settings [11]. Many density-velocity relations are not only dependent on lithology but also on local conditions in each area [12]. Many studies have been carried out to establish density - velocity relations of different lithology, as illustrated in the comparison made by using the Nafe-Drake curve shown in Figure 3 [1]. The results of these results are listed below:

Nafe-Drake curve (Ludwig et al., 1970) [13]:

$\rho\left(\mathrm{g} / \mathrm{cm}^{3}\right)=1.6612 V_{p}(\mathrm{~km} / \mathrm{s})-0.4721 V_{p}^{2}+0.0671 V_{p}^{3}-0.0043 V_{p}^{4}+0.000106 V_{p}^{5}$

Gardner et al., 1974 [2]:

$\rho\left(\mathrm{g} / \mathrm{cm}^{3}\right)=1.74 V_{p}^{0.25}$

Christensen and Mooney (1995) [14]:

$\rho\left(\mathrm{g} / \mathrm{cm}^{3}\right)=0.541+0.360 V_{p}$

Godfrey et al. (1997) [15]:

$\rho\left(\mathrm{g} / \mathrm{cm}^{3}\right)=2.4372+0.0761 V_{p}$

The $2^{\text {nd }}$ polynomial relation of density - velocity for Kf-4 well produced the equation: $\rho\left(\mathrm{g} / \mathrm{cm}^{3}\right)=1.78072+0.000120554 * \mathrm{Vp}+4.86413 \mathrm{E}-9 * \mathrm{Vp}^{\wedge} 2$, with a correlation coefficient $(\mathrm{R})=0.839$, as show in Figure 2 . This equation confers results of density value better than those conferred by Gardner equation , as shown in Table 1 and Figure 4.

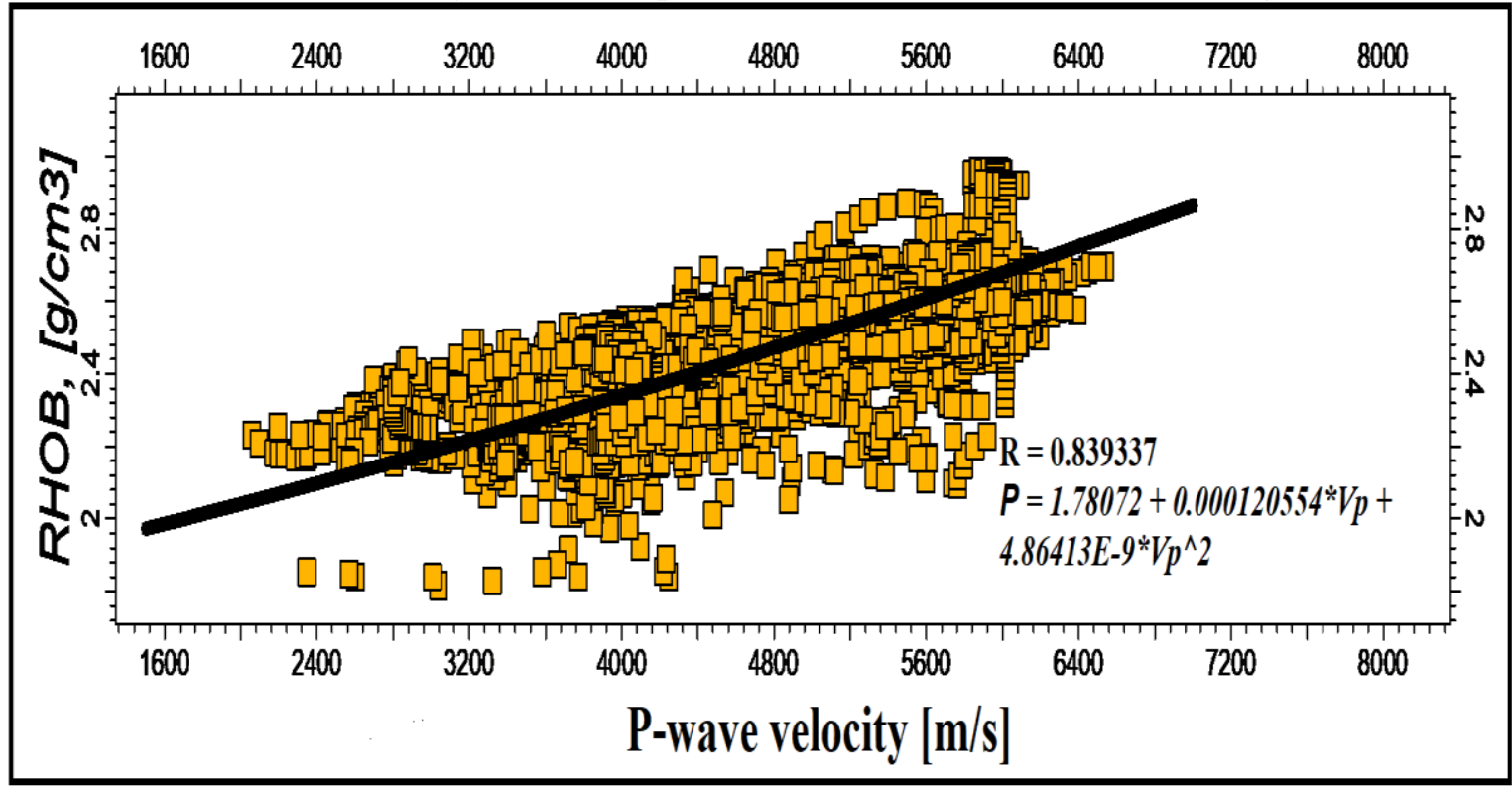

Figure 2- The density- velocity relation depending on the data of Kf-4 well of the Kifl Oil Field, middle of Iraq, where $\rho$ represents density and $\mathrm{Vp}$ represents longitudinal wave velocity. Black line is the best fitting line. 
Table 1- A comparison of density values of well data (RHOB) and those obtained from seismic data depending on Gardner equation and the new empirical equation in $\mathrm{Kf}-4$ well at the Kifl Oil Field.

\begin{tabular}{|c|c|c|c|}
\hline \multirow{2}{*}{ Depth - m } & RHOB & Gardner estimation & $\begin{array}{c}\text { Density-velocity } \\
\text { equation }\end{array}$ \\
\cline { 2 - 4 } & RHolue - g/cm3 & 2.36 \\
\hline 1756.07 & 2.35 & 2.47 & 2.30 \\
\hline 1898.27 & 2.24 & 2.42 & 2.47 \\
\hline 1969.59 & 2.48 & 2.57 & 2.32 \\
\hline 2040.92 & 2.30 & 2.44 & 2.31 \\
\hline 2143.26 & 2.31 & 2.43 & 2.28 \\
\hline 2285.92 & 2.24 & 2.40 & 2.37 \\
\hline 2326.23 & 2.38 & 2.48 & 2.32 \\
\hline 2451.83 & 2.30 & 2.44 & 2.67 \\
\hline 2565.03 & 2.63 & 2.72 & 2.69 \\
\hline 2634.80 & 2.69 & 2.73 & 2.55 \\
\hline 2738.11 & 2.53 & 2.64 & 2.31 \\
\hline 2823.58 & 2.24 & 2.44 & 2.51 \\
\hline 2990.63 & 2.50 & 2.61 & 2.55 \\
\hline 3086.68 & 2.54 & 2.63 & 2.58 \\
\hline 3118.81 & 2.56 & 2.66 & 2.64 \\
\hline 3241.95 & 2.63 & 2.70 & \\
\hline & & & \\
\hline
\end{tabular}

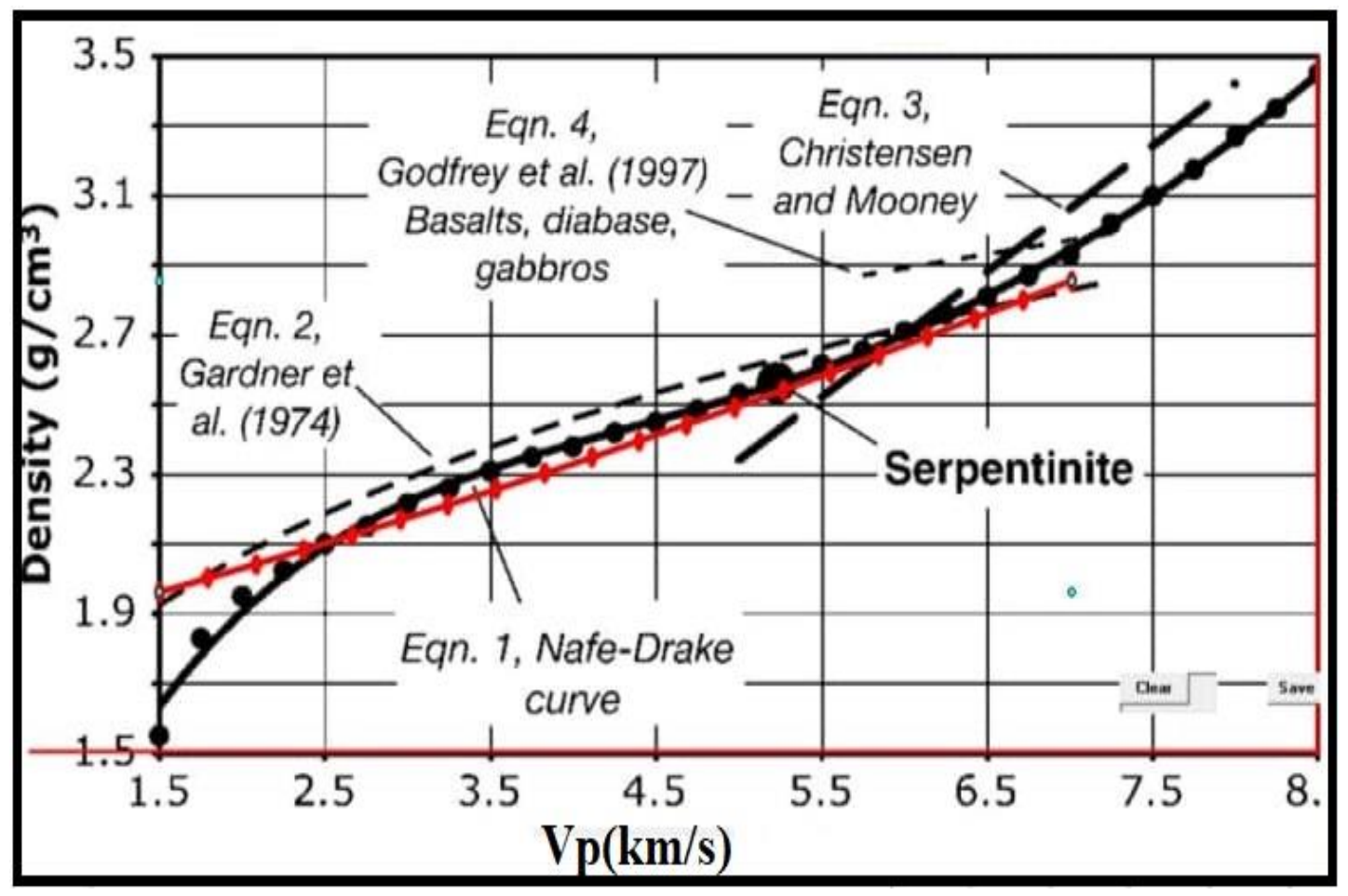

Figure 3- Comparison of the density-velocity curve obtained in Kf-4 well of Kifle Oil Field (The red curve) with some equations usually used to estimate density from seismic data. 


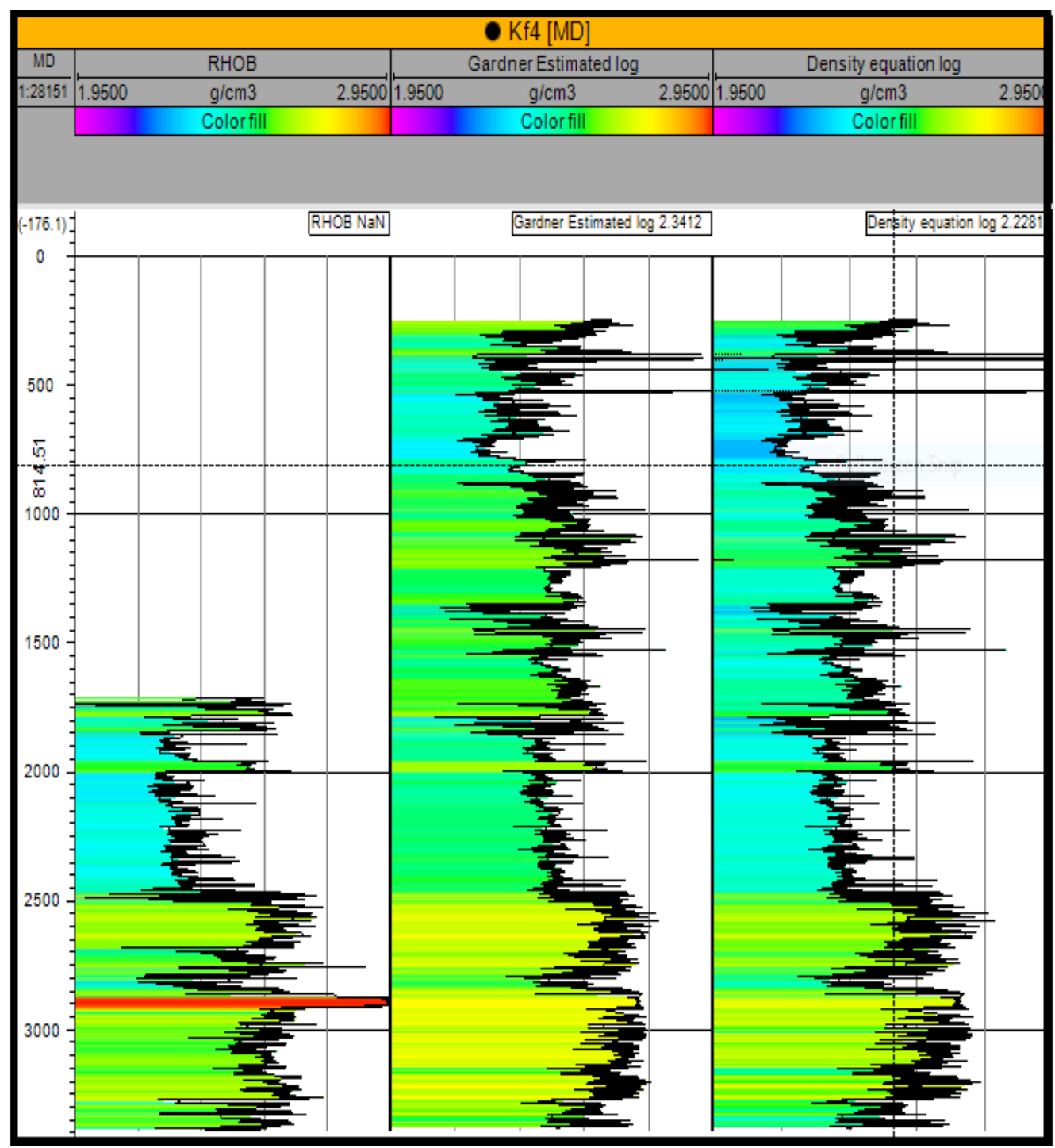

Figure 4-The density values section of RHOB obtained from seismic data using Gardner equation and the new empirical equation in Kf-4 well of Kifle Oil Field.

\section{- The Petrophysical analysis}

Petro-physical analysis is utilized to identify the rock characterization by using the well log data, such as density, gamma ray, neutron, porosity, and other logs. The density log is considered as a function of mineral composition, water saturation, porosity, and hydrocarbon fluid type. It can provide information for reservoir characterization [3]. Authors of some text books prepared tables including density value ranges of some rocks, such as anhydrite (2.82.95), dolomite (2.6-2.8), limestone (2.2-2.75), shale (2.1-2.6), and sandstone (1.9-2.5). These values were used as a control to interpret the density of the studied rocks [16]. The gamma log is a good indicator of shale rock. It determines the emission of natural radiation in the rock. The high value of gamma indicates shale rock because of the high content of potassium, uranium, and thorium, whereas the low value indicates sandstone and limestone [17]. The neutron log depends on the measurement of hydrogen in the formation. It is used to determine the porosity of the formation and gives a good indication of lithology and fluid content in combination with other logs (Figure 5). 


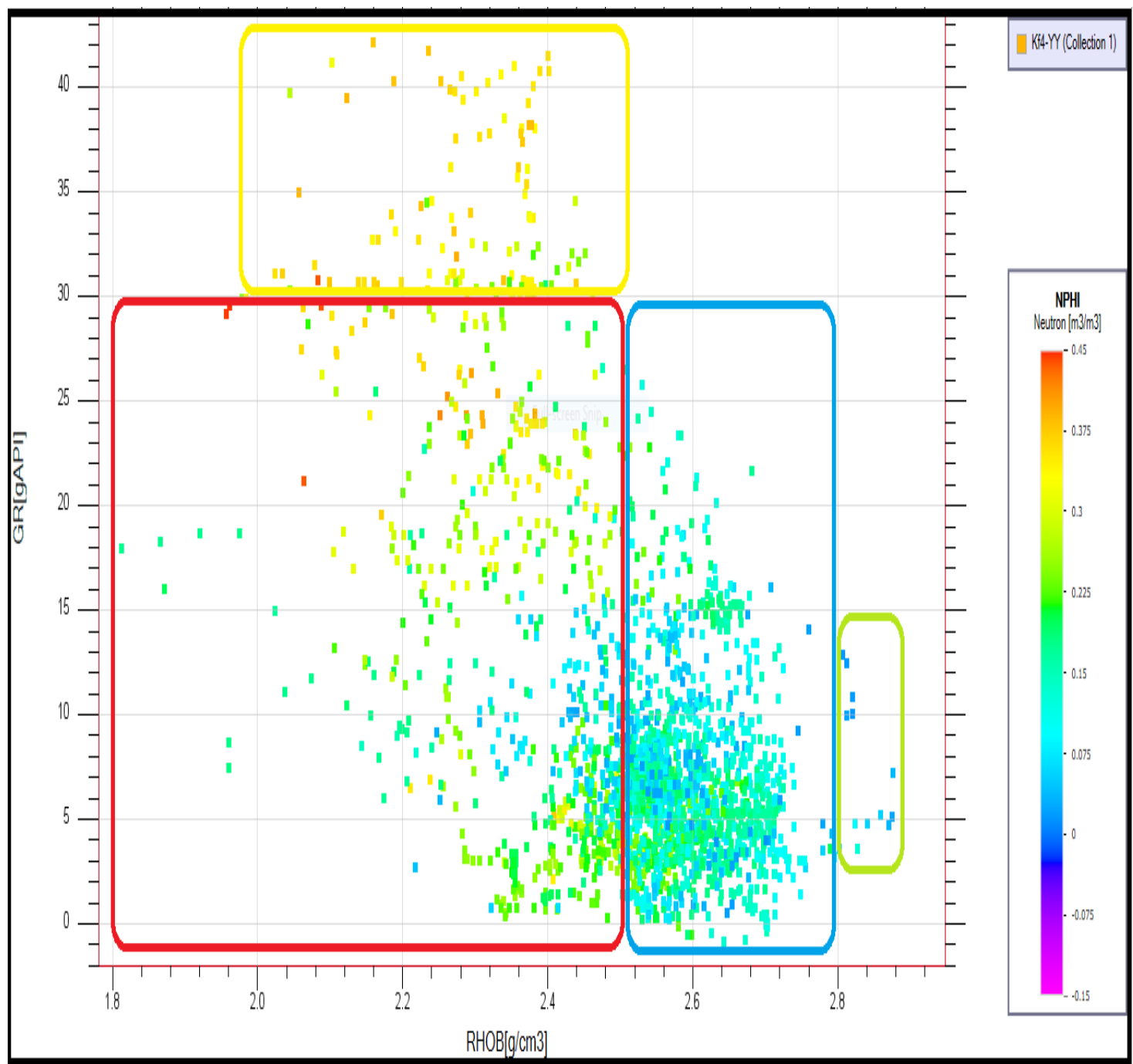

Figure 5- The determination of the lithology of well Kf-4 in Yamama Formation by using a cross-plot of density (RHOB) and gamma (GR) logs. The data points are colored according to their neutron log (NPHI) values. The cross-is divided into four zones; shale zone (yellow), limestone zone (red), dolomite zone (blue), anhydrite zone (green).

\section{- Rock physical analysis}

Rock physics is used to link physical and elastic properties rock. it is understande that the reservoir properties such as lithology, porosity and fluids saturation by the elastic properties that drive from the seismic response such as density, Vp and Vs [18]. where the elastic properties such shear impedance (SI), Lame's parameter $(\lambda)$, bulk modulus (B), shear modulus $(\mu), \mathrm{Vp} / \mathrm{Vs}$ ratio, Acoustic Impedance (AI) and etc . Cross plots between $\mathrm{Vp} / \mathrm{Vs}$ ratio and $\mathrm{AI}$ were constructed. The low value of $\mathrm{Vp} / \mathrm{Vs}$ indicates sandstone and limestone, whereas the high value indicates shale. and the AI of sands exhibit increasing similar values as of the encase of shales where the porosity decrease with increasing the AI value because of increasing in cementation, as shown in Figure 6 [19]. 


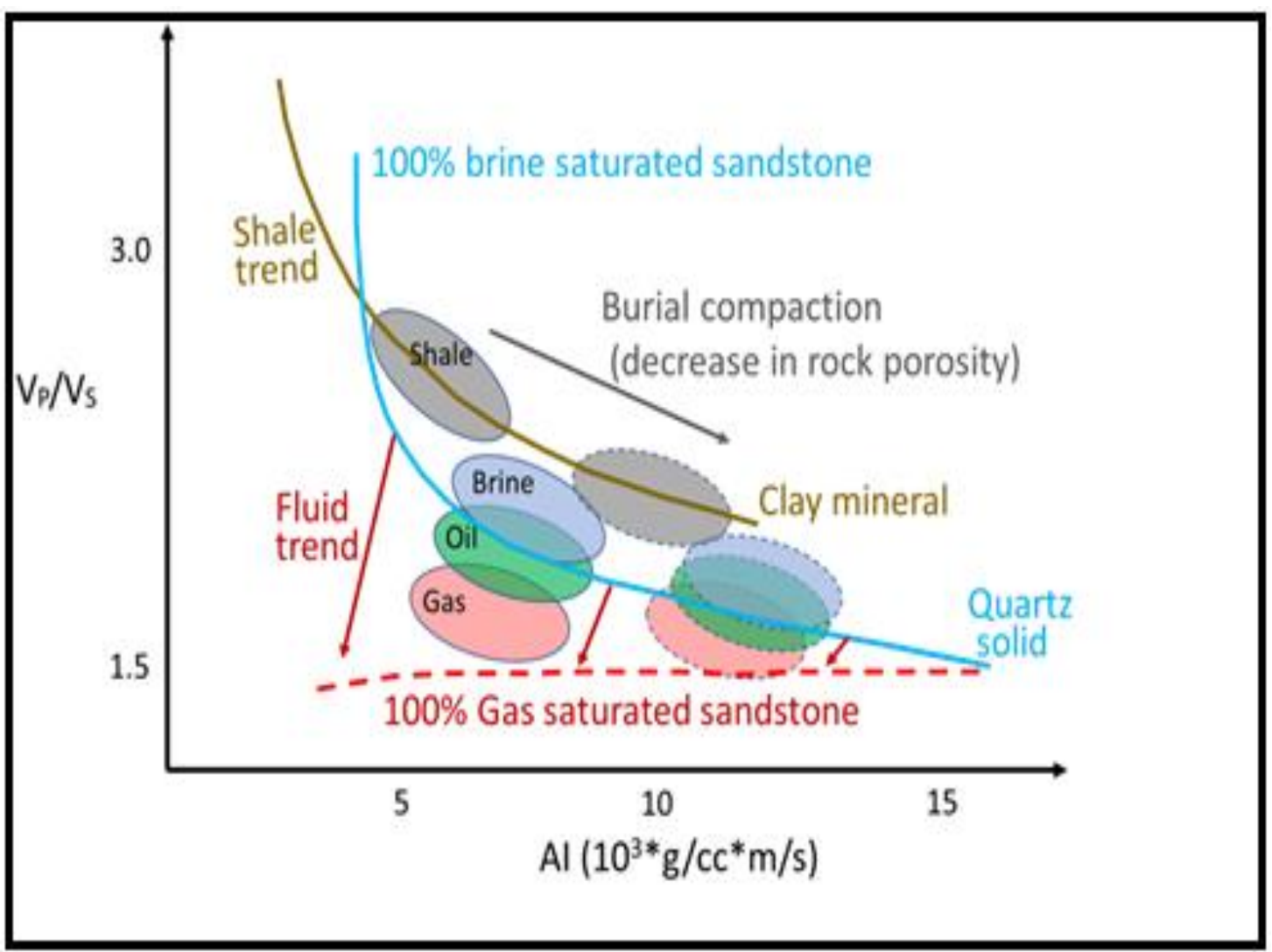

Figure 6- Cross plot of AI vs Vp/Vs space for brine and hydrocarbon-saturated sandstones and shales, after [16].

The cross plots were used to predict the lithology of Yamama Formation. The data points were colored with gamma log values and the results are presented in Figure 7. Another cross plot was produced for the prediction of Yamama Formation lithology, depending on the density $\log$ values, to provide higher accuracy to the results (Figure 8).

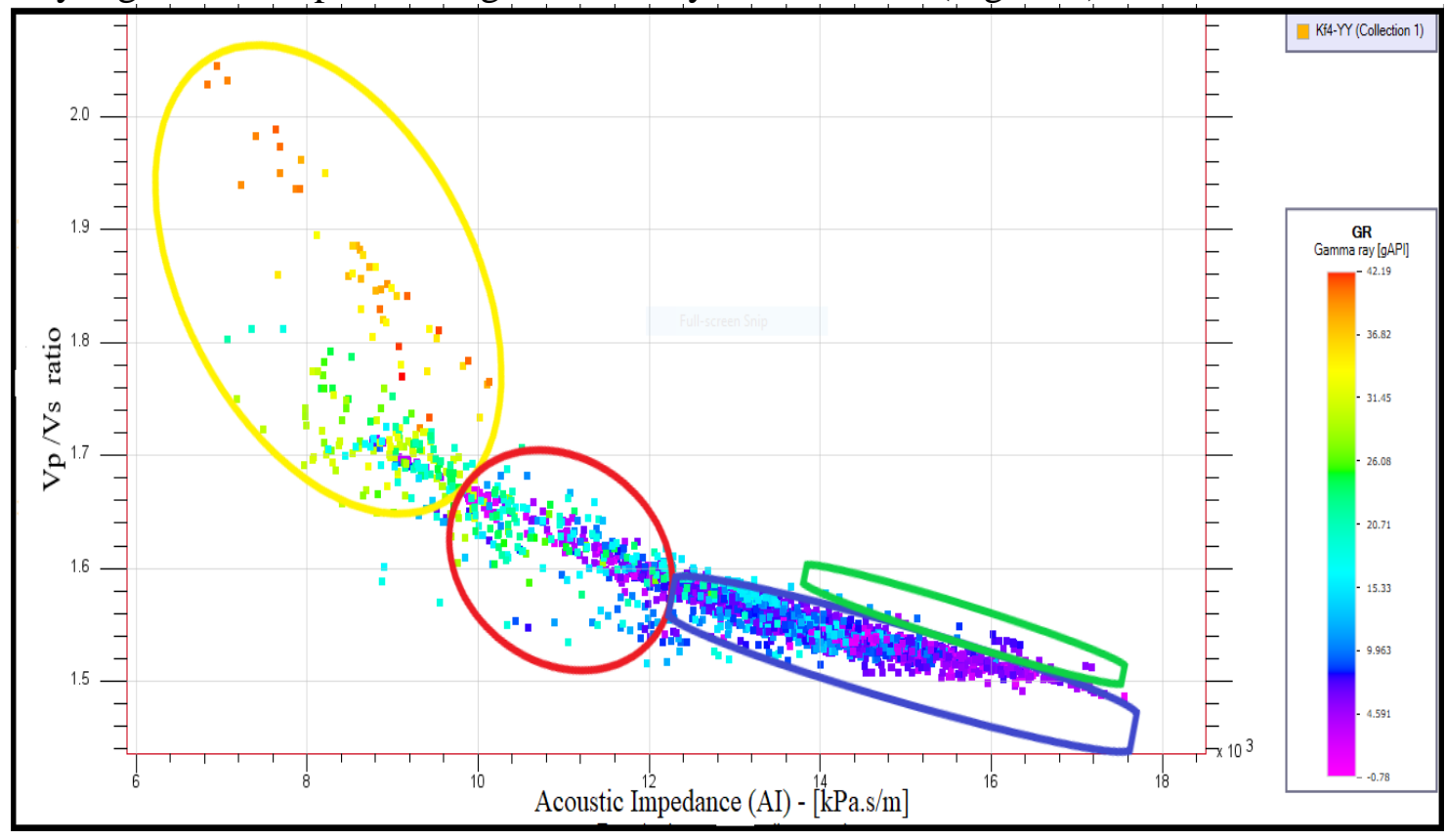

Figure 7- Cross plot of $\mathrm{Vp} / \mathrm{Vs}$ versus acoustic iimpedance (AI) of Kf-4 well. The data points are colored according to their gamma $\log (\mathrm{GR})$ values. Four zones are interpreted; shale zone (yellow), limestone zone (red), dolomite zone (blue), anhydrite zone (green). 


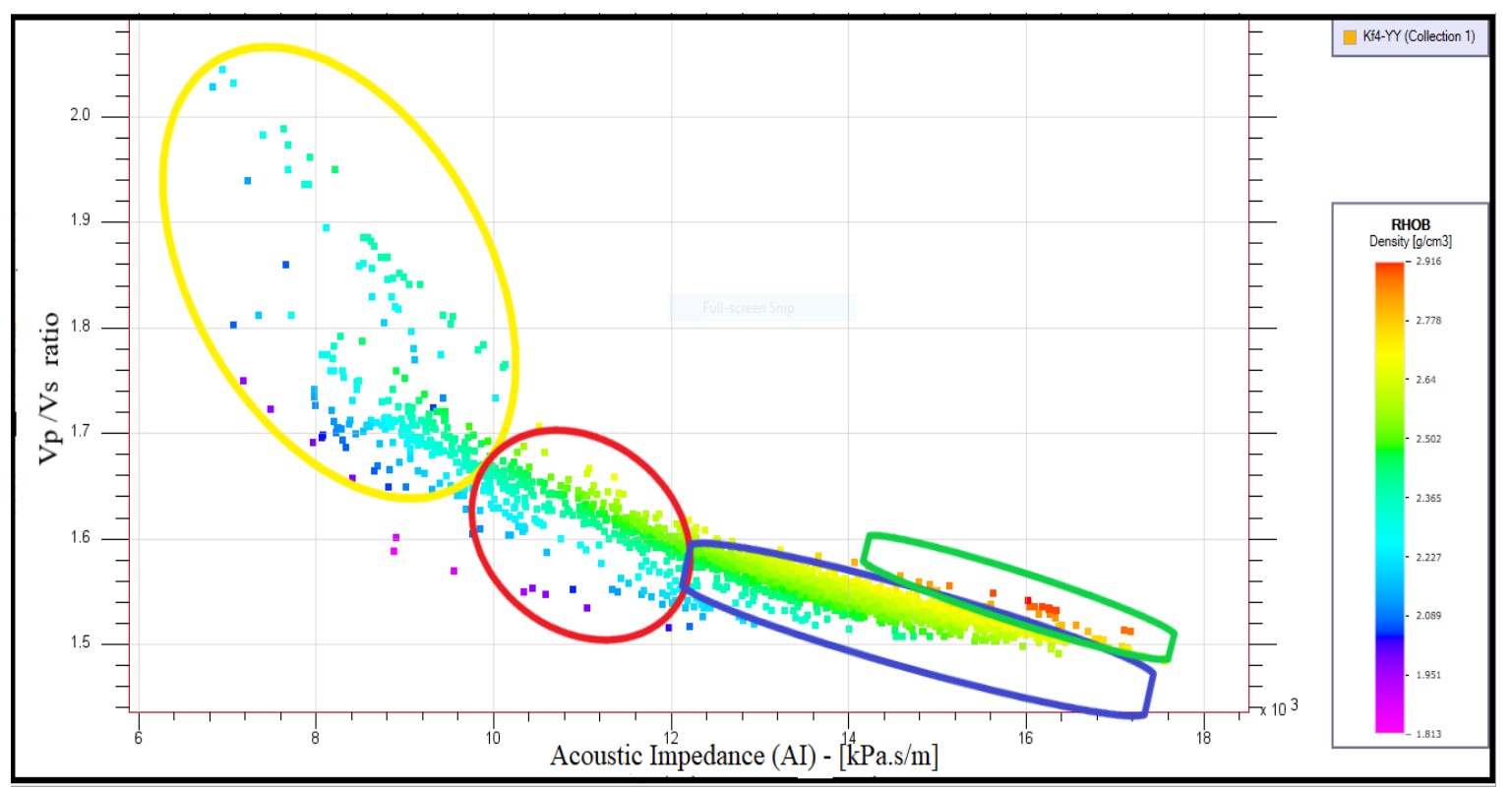

Figure 8- Cross plot of $\mathrm{Vp} / \mathrm{Vs}$ versus acoustic impedance (AI) of Kf-4 well. The data point are colored according to their density log (RHOB) values on which four zones have been interpreted, where the Shale zone (yellow), Limestone zone (red), Dolomite (blue), Anhydrite (green).

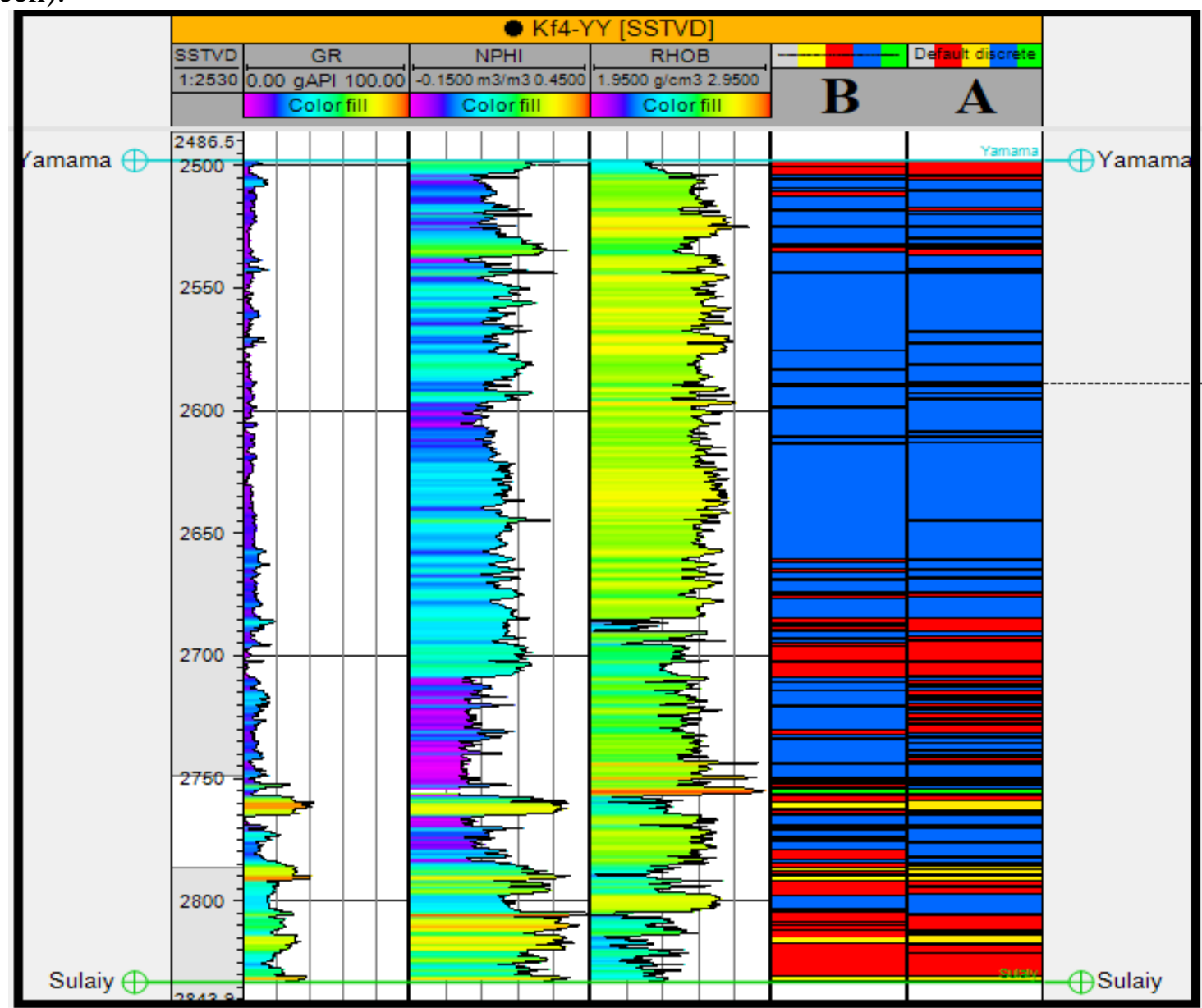

Figure 9- The well log section of (GR-NPHI- RHOB) logs and the lithological column of well Kf-4. (A) the lithological column of petro-physics analysis. (B) the lithological column of rock physics analysis; shale zone (yellow), limestone zone (red), dolomite zone (blue), anhydrite zone (green). 
Due to the physical properties achieved in this study, Yamama Formation was divided, from top to bottom, into five units. The upper unit is represented by a thin layer of limestone $(2498-2503 \mathrm{~m})$. The second layer is a thick layer of dolomite laminated with thin beds of limestone and anhydrite at a depth of $2504-2684 \mathrm{~m}$. The third layer is found at a depth of 2685-2755m, composed of limestone interbedded with thin layers of dolomite. The fourth layer is positioned at a depth of $2756-2765 \mathrm{~m}$, represented by interbedded layers of anhydrite, limestone, and shale. The deepest part of the formation, i.e. the fifth layer, is represented by interbedded layers of limestone, dolomite, and shale with a depth of 2766-2834m (Figure 9).

\section{Conclusions}

The density values were calculated from the equation obtained for density-velocity relation in Kf- 4 well. Accurate values were obtained with best fitting to the measured density $\log$ in comparison with those determined by using Gardner equation. The density-velocity curve of Kf-4 well approximately matched the Nafe- Drake curve.

It was found that Yamama Formation consists of limestone, dolomite, shale, and anhydrite rocks. Yamama Formation, according to the physical properties, could be divided into five units. The petro-physics and rock physics analyses of the available well log data showed good results concerning the lithology of the Formation.

\section{References}

[1] Brocher, T. M. "Empirical relations between elastic wave speeds and density in the Earth's crust". Bulletin of the seismological Society of America, vol. 95, no. 6, pp. 2081-2092, 2005.

[2] Gardner, G. H. F., Gardner, L. W., \& Gregory, A. R. "Formation velocity and density-The diagnostic basics for stratigraphic traps". Geophysics, vol. 39, no. 6, pp. 770-780, 1974.

[3] Quijada, M. F., \& Stewart, R. R. "Density estimations using density-velocity relations and seismic inversion". CREWES Res Rep, vol. 19, pp. 1-20, 2007.

[4] Azeem, T., Chun, W. Y., Khalid, P., Qing, L. X., Ehsan, M. I., Munawar, M. J., \& Wei, X. "An integrated petrophysical and rock physics analysis to improve reservoir characterization of Cretaceous sand intervals in Middle Indus Basin", Pakistan. Journal of Geophysics and Engineering, vol. 14, no. 2, pp. 212-225, 2017.

[5] Avseth, P., Mukerji, T., Mavko, G., \& Dvorkin, J. "Rock-physics diagnostics of depositional texture, diagenetic alterations, and reservoir heterogeneity in high-porosity siliciclastic sediments and rocks-A review of selected models and suggested work flows". Geophysics, vol. 75, no. 5, pp. 75A31-75A47, 2010.

[6] Hermana, M., Lubis, L. A., Ghosh, D. P., \& Sum, C. W. "New rock physics template for better hydrocarbon prediction", In Offshore Technology Conference Asia. Offshore Technology Conference. p 1-6, 2016.

[7] Jassim, Saad Z. and Goff, Jeremy C., Geology of Iraq, Czech Republic, ISBN 80-7028287-8, 2006 , p. $50-74$.

[8] Al-Banna A.S. and Ali K.K. "The Transition Tectonic Zone between the Two Parts of the Platform in Iraq: A Review Study", Iraqi Journal of Science, vol. 59, no. 2c, pp. 1086-1092, 2018.

[9] Oil exploration company, Final report of the Kifl oil field. p. 169 - 173, 2015.

[10] Al-Ameri, T. K., Pitman, J., Naser, M. E., Zumberge, J., \& Al-Haydari, H. A. "Programed oil generation of the Zubair Formation, Southern Iraq oil fields: results from Petromod software modeling and geochemical analysis". Arabian Journal of Geosciences, vol. 4, no. 7-8, pp. 12391259, 2011.

[11] Ojha, M., \& Sain, K., "Velocity-porosity and velocity-density relationship for shallow sediments in the Kerala-Konkan basin of western Indian margin". Journal of the Geological Society of India, vol. 84, no. 2, pp. 187-191, 2014.

[12] Hilterman, F. J. "Seismic amplitude interpretation", Society of Exploration Geophysicists and European Association of Geoscientists and Engineers. p 243, 2-8, 2001. 
[13] Brocher, T. M., "Key elements of regional seismic velocity models for long period ground motion simulations". Journal of seismology, vol. 12, no. 2, pp. 217-221, 2008.

[14] Christensen, N. I., and W. D. Mooney "Seismic velocity structure and composition of the continental crust: a global view”, J. Geophysics. Res., vol. 100, pp. 9761-9788, 1995.

[15] Godfrey, N. J., B. C. Beaudoin, S. L. Klempererthe Mendocino Working Group USA, and S. L. Klemperer, "Ophiolitic basement to the Great Valley forearc basin, California, from seismic and gravity data: implications for crustal growth at the North American continental margin", Geol. Soc. Am. Bull., vol. 109, pp. 1536-1562, 1997.

[16] Akhter, G., Khan, Y., Bangash, A. A., Shahzad, F., \& Hussain, Y., "Petrophysical relationship for density prediction using Vp \& Vs in Meyal oilfield, Potwar sub-basin, Pakistan". Geodesy and Geodynamics, vol. 9, no. 2, pp. 151-155, 2018.

[17] Nwozor, K. K., Onuorah, L. O., Onyekuru, S. O., \& Egbuachor, C. J., "Calibration of Gardner coefficient for density-velocity relationships of tertiary sediments in Niger Delta Basin". Journal of Petroleum Exploration and Production Technology, vol. 7, no. 3, pp. 627-635, 2017.

[18] Nasser, M., \& Sinton, J. B., "Integrating rock physics and full elastic modeling for reservoir characterization", In SEG Technical Program Expanded Abstracts 2011 (pp. 2886-2890). Society of Exploration Geophysicists, 2011.

[19] Avseth, P., \& Veggeland, T., "Seismic screening of rock stiffness and fluid softening using rockphysics attributes". Interpretation, vol. 3, no. 4, pp. SAE85-SAE93, 2015. 